\title{
Anti-Cancer Activity and Molecular Docking of Some Pyrano[3,2-c]quinoline Analogues
}

\author{
Abdeltawab M. Saeed1*, Ibrahim M. Abdou1, Alaa A. Salem¹, Mohammad A. Ghattas', \\ Noor Atatreh${ }^{2}$, Shaikha S. AlNeyadi ${ }^{1}$
}

${ }^{1}$ Department of Chemistry, College of Science, UAE University, Al Ain, UAE

${ }^{2}$ College of Pharmacy, Al Ain University of Science and Technology, Al Ain, UAE

Email:^tawab681@hotmail.com,shaikha.alneyadi@uaeu.ac.ae

How to cite this paper: Saeed, A.M., Abdou, I.M., Salem, A.A., Ghattas, M.A., Atatreh, N. and AlNeyadi, S.S. (2020) Anti-Cancer Activity and Molecular Docking of Some Pyrano[3,2-c]quinoline Analogues. Open Journal of Medicinal Chemistry, 10, 1-14. https://doi.org/10.4236/ojmc.2020.101001

Received: February 1, 2020

Accepted: March 2, 2020

Published: March 5, 2020

Copyright $\odot 2020$ by author(s) and Scientific Research Publishing Inc. This work is licensed under the Creative Commons Attribution International License (CC BY 4.0).

http://creativecommons.org/licenses/by/4.0/

\begin{abstract}
Quinoline analogues exhibited diversified biological activities depending on the structure type. A number of natural products with pyrano[3,2-c]quinolone structural motifs and patented chromenes were reported as promising cytotoxic agents. A molecular docking study was employed to investigate the binding and functional properties of 3-amino pyranoquinolinone $2 \mathrm{a}-\mathrm{c}$ as anti-cancer agents. The three 3-amino pyranoquinolinone $2 \mathrm{a}-\mathrm{c}$ showed an interesting ability to intercalate the DNA-topoisomerase complex and were able to obtain energetically favorable binding modes $(-8.3--7.5 \mathrm{kcal} / \mathrm{mol})$. Compound $2 \mathrm{c}$ containing butyl chain superiority over the other two compounds $2 \mathrm{a}-\mathrm{b}$ which appeared to be involved in arene- $\mathrm{H}$ interactions with the two dG13 aromatic centers. The butyl chain also appeared to be immersed into a side subpocket formed by the side chains of Asn520 and Glu522 and the backbone amide of Arg503, Gly504, Lys505 and Ile506. Hence, the 3 -amino pyranoquinolinone $2 \mathrm{c}$ used as starting material to prepare derivatives of pyrano[3,2-c] quinolone containing 1,2,4-triazine ring $4 \mathrm{a}-\mathrm{b}$ which will enhance the anti-cancer activity. Pyrano[3,2-c]quinoline-2,5-diones $2 \mathrm{a}-\mathrm{c}$ and 4a-b were evaluated in vitro on cell lines Ehrlich Ascites carcinoma cells (EAC), liver cancer cell line Hep-G2 and breast cancer cell line MCF-7 for the development of novel anticancer agents. The screening results revealed that compounds $4 \mathrm{a}-\mathrm{b}$ were found most active candidates as anticancer agents.
\end{abstract}

\section{Keywords}

Pyrano[3,2-c]quinoline, Molecular Docking, Anticancer 


\section{Introduction}

Over the past few years, several quinoline containing compounds are reportable as potential antitumor agents. Further, Quinoline scaffold plays a crucial role in antitumor drug development as their derivatives have shown excellent results through different mechanism of action such as growth inhibitors by cell cycle arrest, apoptosis, inhibition of angiogenesis, disruption of cell migration, andmo dulation of nuclear receptor responsiveness. The anti-cancer potential of many of these derivatives has been demonstrated on various cancer cell lines. The strength of quinoline motif in anticancer drug development is evident from clinically used anticancer drugs like Camptothecin, Topotecan and Irinotecan, etc. [1].

Pyranoquinolones and fused pyrano[3,2-c]quinolone moities are widely available in bioactive natural products, synthetic products as well as pharmaceutical agents [2]. Pyrano[3,2-c] quinolones are primarily notable for their anticancer activity [3] [4], along with antimalarial [5], antibacterial [6], antiinflammatory [7], and antifungal [8] properties. Pyrano[3,2-c]quinolone is a core structural motif present in many alkaloids possessing important therapeutic activities [9]. For instance, huajiaosimuline (A, Figure 1), a potent and selective anticancer agent towards breast cancer, and zanthosimuline (B, Figure 1), an anticancer agent having activity against multidrug resistant KB-VI cancer cells, were both isolated from Zanthoxylum simulans [10].

Heterocyclic scaffolds, particularly nitrogen-containing heterocyclic compounds, play an important role in the design of novel drugs because of their utility for various biological receptors with a high degree of binding affinity. Among the heterocycles, the triazines with their numerous biological profile, occupy a prominent position [11]. The 1,2,4-triazine ring as one of the most ubiquitous heterocycles in Nature, and it has been reported to possess a broad spectrum of biological properties, including anticonvulsant [12], neuroprotective [13], anxiolytic [14], antiparkinson [15], antidepressant [16], anti-inflammatory [17], antimicrobial [18] activities. In addition, there are also many reports indicating significant anticancer properties for the 1,2,4-triazine fragment. For example, tirapazamine (C, Figure 1 ) is currently in various clinical trial phases for the treatment of human non-small cell, cervical, ovarian, head and neck cancers. Tirapazamine works by inducing DNA damage in poorly oxygenated tumor cells [19]. With this background and on the basis of that the pyrano[3,2-c]quinolone moieties reveal broad spectrum of biological activities and exhibit cytotoxicity against cancer cells. In the present work, pyrano[3,2-c]quinolone containing 1,2,4-triazine ring were evaluated as anticancer agents toward human cancer cell lines Ehrlich Ascites carcinoma cells (EAC), Liver cancer cell line Hep-G2 and Breast cancer cell line MCF-7. A molecular docking study was employed to investigate the binding and functional properties of Pyranoquinolines derivatives as topoisomerase II $\beta$ (TOP2B) inhibitory activity. 


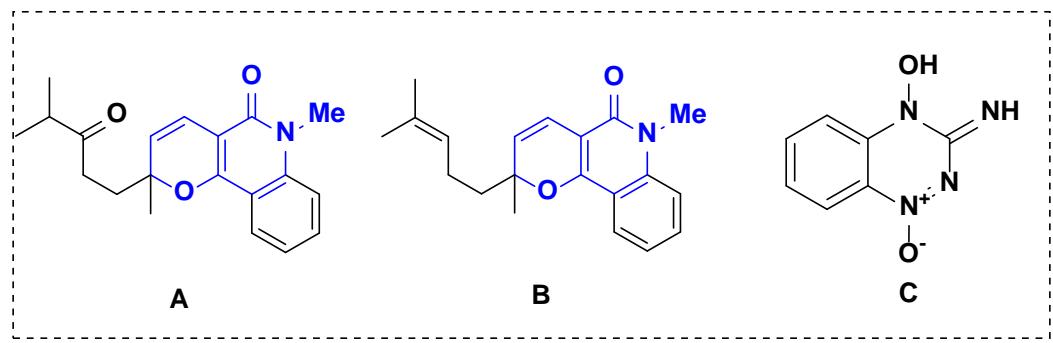

Figure 1. Naturally occurring and bioactive pyrano[3,2-c]quinolone molecules (A - E): (A) huajiaosimuline, a selective anticancer agent (breast); (B) zanthosimuline, an anticancer agent against multidrug resistant KB-VI cancer cells; (C) Structure of tirapazamine.

\section{Material and Methods}

\subsection{Anticancer Activity for Liver Cancer Cell Line Hep-G2 and Breast Cancer Cell Line MCF-7}

\subsubsection{Cell Cultures and Treatments}

Liver cancer cell line Hep-G2 and breast cancer cell line MCF-7 were obtained from the American type culture collection (Rockville, Mary land, USA). Cells were grown in RPMI-1640 medium supplemented with $10 \%$ fetal bovine serum, $1 \%$ nonessential amino acid solution and $1 \%$ penicillin-streptomycin solution $(10,000 \mathrm{U}$ of penicillin and $10 \mathrm{mg}$ of streptomycin in $0.9 \% \mathrm{NaCl})$ in a humidified atmosphere of $5 \% \mathrm{CO}_{2}$ and $95 \%$ air at $35^{\circ} \mathrm{C}$. The cells were cultured in $25 \mathrm{~cm}^{2}$ cell culture flasks. For experimental purposes, cells were cultured in 96-well plates $(0.2 \mathrm{~mL}$ for cell solution/well). The optimum cell concentration as determined by the growth profile of the cell line was $10 \times 10^{5}$ cells $/ \mathrm{mL}$ (cells were allowed to attach for $24 \mathrm{~h}$ before treated with tested compounds). The stock solution was filtered with Minisart filters Merck (Darmstadt, Germany) $(0.22 \mu \mathrm{m})$. Working two-fold serially diluted test material $(\mu \mathrm{m})$ was prepared. Cells monolayers were washed with PBS (phosphate buffer saline $\mathrm{pH}=7.2$ ) and the additional serially diluted material was dispensed to the precultured plates for the determination of test material's toxicity [20].

\subsubsection{MTT Assay for Cytotoxicity}

MTT assay is a sensitive, quantitative and reliable colorimetric method that measures viability of cells. The assay is based on the ability of mitochondrial lactate dehydrogenase enzymes (LDH) in living cells to convert the water soluble substrate 3-(4,5-dimethyl-2-thiazolyl)-2,5-diphenyltetrazolium bromide (MTT) used as $5 \mathrm{mg} / \mathrm{mL}$ in a dark blue formazan which is water-insoluble. Dimethyl sulfoxide is added to dissolve the insoluble purple formazan product into a colored solution. The absorbance of this colored solution can be quantified by measuring it using spectrophotometer at a wavelength usually between 500 and $600 \mathrm{~nm}[21]$.

\subsubsection{Method}

Test and standard materials were 2 fold serially diluted on precultuled cell lines 
for $24 \mathrm{~h}$ treatment at $37^{\circ} \mathrm{C}$ post decanting growth medium. Treated cell lines were microscopically examined for detecting morphological changes and detached cells. Dead cells were washed out using phosphate buffer saline $\mathrm{pH}=7.2$ \pm 0.2 (PBS- $0.05 \%$ Tween). Cells were incubated in 96 wells plates $\left(1 \times 10^{6}\right.$ cells $/ \mathrm{mL}$ ) for different times periods $(24,48$ and $72 \mathrm{~h})$. At the required time point $50 \mu \mathrm{L}$ of supematant was aspirated, added to another well and mixed with $50 \mu \mathrm{L}$ of the substrate buffer containing MTT dye (provided in the Promega Kit). Plated were incubated for $3-4 \mathrm{hrs}$ at $37^{\circ} \mathrm{C}$. developed intra-cytoplasmic MTT formazan crystals were dissolved using $0.05 \mathrm{~mL}$ dimethyl sulphoxide (DMSO) for $30 \mathrm{~min}$ on plate shaker optical densities were read using (Biotek 8000, USA) ELISA plate reader.

\subsubsection{Calculations}

$\mathrm{IC}_{50}$ of test compounds was determined using Master-plex-2010 program. Data were reported for three independent experiments [22]. Cell viability percentage was calculated as follows:

Cell viability percentage $=(\mathrm{OD}$ of treated cells $/ \mathrm{OD}$ of untreated cells $) \times 100$ [23].

\subsection{Anticancer Activity for EAC Cells}

EAC cells were maintained by weekly intraperitoneal transplantation of $2.5 \times 10^{5}$ cells in mice. The tumor is characterized by a moderately rapid growth, which leads to the death of the mice in about 20 days due to the distal metastasis. Ascites was withdrawn under aseptic conditions from the peritoneal cavity of tumor bearing mice by needle aspiration after 7 days of EAC cells inoculation. To adjust the number of EAC cells/mL, tumor cells obtained were diluted several times with normal saline. EAC viable cells were counted by trypan blue exclusion method where $10 \mu \mathrm{l}$ trypan blue $(0.05 \%)$ was mixed with $10 \mu \mathrm{l}$ of the cell suspension. Within $5 \mathrm{~min}$, the mixture was spread onto haemocytometer, covered with a cover slip and then the cells were examined under microscope. Dead cells were stained blue, viable cells were not. Cell suspension was adjusted to contain $2.5 \times 10^{5}$ viable cells $/ \mathrm{ml}$. EAC cells, RPMI medium drugs, and DMSO were added in sterile test tubes according to trypan blue exclusion method [24]. The cells were incubated for two hours at $37^{\circ} \mathrm{C}$ under a constant over lay of $5 \%$ $\mathrm{CO} 2$. EAC viable cells were counted by trypan blue exclusion using haemocytometer as mentioned above. The cell surviving fraction was calculated from the relation $\mathrm{T} / \mathrm{C}$; where $\mathrm{T}$ and $\mathrm{C}$ represent the number of viable cells in a unit volume and the number of total (viable + dead) cells in the same unit volume, respectively. The in vitro cytotoxicity was performed against two different human cancer cell lines namely: Liver Hep-G2 and Breast MCF-7. Comparison between new compounds is carried out to evaluate their toxicity against Liver Hep-G2 and Breast MCF-7 cancer cell lines. Cell viability assessment using the MTT method indicated a significant difference between the synthesized compounds and reference drug, 5-flurouracil. 


\subsection{Docking Analysis}

The crystal structure of the Topoisomerase-II-DNA-inhibitor complex was obtained from the protein data bank (PDB: 4G0V [25]). The ternary complex was then checked for any missing atoms/residues via the protein preparation module in MOE [26]. All solvent molecules and all hetero ligands were removed. Using the Protein Preparation Wizard [26] the Topoisomerase-II-DNA complex was fully prepared via creating bonds and adding hydrogens. Subsequently, partial charges were assigned on all atoms and protonation states were predicted for ionizable groups. The binding pocket was identified by the co-crystallized ligand and a grid box was produced in Glide using the Receptor Grid Generation module [26] [27]. Ligands were prepared in Maestro [27] [28] via the LigPrep module using the default settings. The dominant ionization states at $\mathrm{pH}$ range of 7.0 \pm 2.0 were generated for ionizable functional groups. Next, ligands were docked into the binding site of the previously prepared protein-DNA complex using the Glide software [26] [27], where the extra-precision (XP) Algorithm [29] was used for conformational sampling. Afterwards, generated poses were scored via the Glide_XP scoring function which includes terms for van der Waals, hydrogen bond, electrostatic interactions, desolvation penalty and penalty for intra-ligand contact [29].

\section{Results and Discussion}

\subsection{Chemistry}

Pyrano[3, 2 c] quinoline analogues $2 \mathrm{a}-\mathrm{c}$ and $\mathbf{4 a}-\mathrm{b}$ were synthesized as described in the literature [30]. The nitro-derivative $1 \mathrm{a}-\mathrm{c}$ were reduced with tin and concentrated hydrochloric acid at $130^{\circ} \mathrm{C}$ to produce $N$-alkyl-3-aminopyrano [3,2-c] quinoline-2,5-diones $2 \mathrm{a}-\mathrm{c}$ in $70 \%-79 \%$ yield (Figure 2). The intermediate $3 \mathrm{c}$ was generated in situ by the condensation of 3 -aminoquinolinones $2 \mathrm{c}$ with dimethylformamid-dimethylacetal (DMF-DMA). The structure of enamine $3 \mathrm{c}$ comprises variable electron-deficient centers and it is expected to be quite reactive towards nucleophilic reagents. The formation of triazinopyranoquino-linones 4a-b takes place initially via Michael addition to the olefinic carbon of enamine $3 \mathrm{c}$ followed by elimination of dimethylamine, then heterocyclized to give $4 \mathrm{a}-\mathrm{b}$ in a good yield $(70 \%-90 \%)$

\subsection{Docking Study}

A molecular modelling study was initiated in order to support the assumed mode of action for tested compounds $2 \mathrm{a}-\mathrm{c}$ and optimize a reliable model for predicating novel effective antitumour hits. The design of the 3-amino pyranoquinolinone $2 \mathrm{a}-\mathrm{c}$ compounds was based on the anticancer quinolone structure. Voreloxin, a quinolone compound, is an antineoplastic agent that reached the clinical trial. [31] Voreloxin was observed to work through intercalating DNA and poisoning topoisomerase II via forming a protein-DNA-inhibitor complex [31]. Similar to the standard intercalating agent doxorubicin, the resulting ternary 


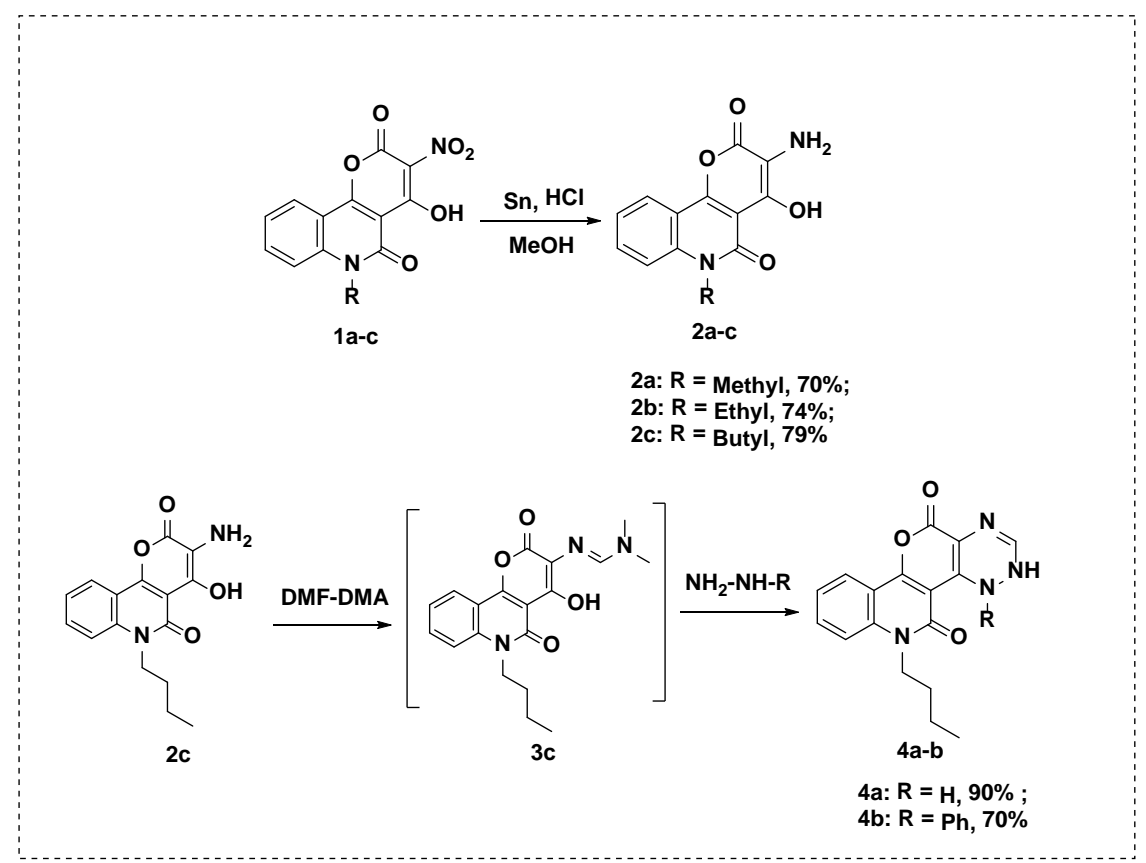

Figure 2. Synthetic of compounds $2 \mathrm{a}-\mathrm{c}$ and $4 \mathrm{a}-\mathrm{b}$.

complex will consequently cause DNA fragmentation and finally apoptosis [32] [33]. Based on structural similarities between our compounds and quinolones, it was just sensible to propose that the 3-amino pyranoquinolinone compounds exert their antitumor activity via binding to the topoisomerase-II-DNA complex through the intercalation mechanism. The 3-amino pyranoquinolinone 2a-c along with the reference intercalating agent doxorubicin were docked into the topoisomerase-II-DNA complex. The resultant docking scores of the test compounds and reference ligands along with their ligand efficiency score are shown in Table 1. Interestingly, the three 3 -amino pyranoquinolinone $2 \mathrm{a}-\mathrm{c}$ were able to obtain energetically favorable binding modes $(-8.3--7.5 \mathrm{kcal} / \mathrm{mol})$. The best scorer $2 \mathrm{c}$ was nicely placed on top of the co-crystalized ligand, intercalating the double stranded DNA (Figure 3(A)). Several stacking and hydrogen bonding interactions appear to contribute to the 3 -amino pyranoquinolinone intercalation ability. The planar tricyclic system of these compounds seemed to give them a great capacity to slide in between the DNA bases and to make $\pi-\pi$ interaction with the surrounding nitrogen bases, Figure 3(B). Additionally, the 3-amino pyranoquinolinone compounds were capable of forming two hydrogen bonds with the dT9 deoxyribose and phosphate groups through their amine and another electrostatic interaction with the topoisomerase Asn778 side chain through their aromatic hydrogen. Compound $2 \mathrm{c}$ has an extended alkyl side chain, compared to $2 \mathrm{a}$ and $\mathbf{2 b}$, which appeared to be involved in arene-H interactions with the two dG13 aromatic centers. The butyl chain also appeared to be immersed into a side subpocket formed by the side chains of Asn520 and Glu522 and the backbone amide of Arg503, Gly504, Lys505 and Ile506. For these two reasons, the butyl chain seems to be the main responsible factor for $2 c$ superiority over the 
Table 1. Docking scores of n-l docked into the Topoisomerase-DNA complex.

Compound No.

${ }^{\star}$ Ligand efficiency $=$ Glide_XPSCore/number of heavy atoms.

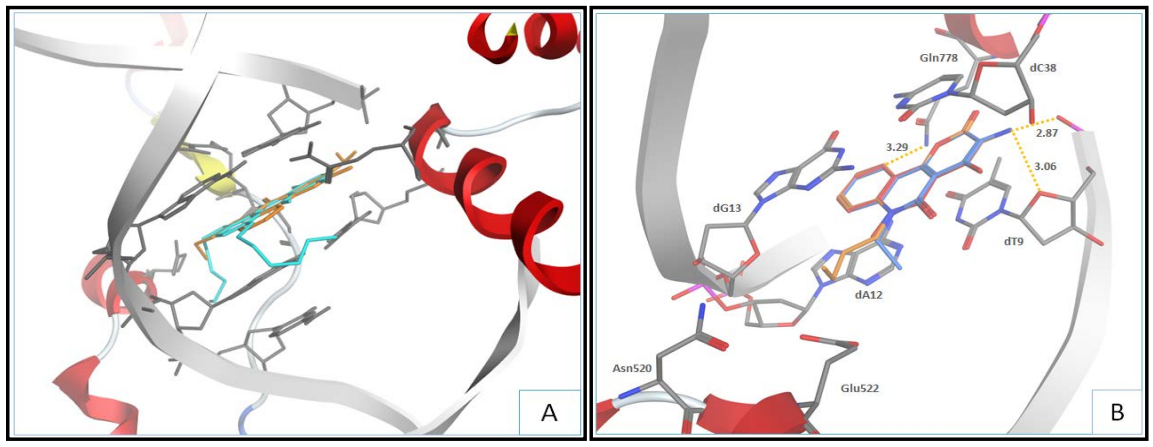

Figure 3. (A) The predicted binding pose of $2 \mathrm{c}$ (orange sticks) aligned on the co-crystallized ligand (cyan sticks) of the topoisomerase-II-DNA crystal structure; (B) Docked poses of $\mathbf{2 a}$ (red sticks), $\mathbf{2 b}$ (blue sticks) and $\mathbf{2 c}$ (orange sticks) aligned on each other and shown to intercalate the DNA double strand (gray sticks) in an identical manner. The picture was generated by MOE. [26] Hydrogen bonding is shown as yellow dotted lines.

other two compounds 2a-b. As it can be noticed in Figure 3(B), this alkyl group is pointed towards the side chains of Asn520 and Glu522; meaning that extend- 
ing the $2 \mathrm{c}$ aliphatic chain with a polar group may result in a new electrostatic interaction, with topoisomerase II that can significantly boost 3-amino pyranoquinolinone compounds $2 \mathrm{a}-\mathrm{c}$ potency. Thus, there is room for improvement with regards to these compounds binding with topoisomerase-DNA complex through their aliphatic chain. Although our compounds scored higher binding energies than doxorubicin (Table 1), they were able to obtain a very good ligand efficiency score $(\leq-0.38 \mathrm{kcal} / \mathrm{mol})$ in comparison to the reference ligand $(-0.26$ $\mathrm{kcal} / \mathrm{mol}$ ). Ligand efficiency accounts for the binding energy scored by each atom, indicating that our compounds have better leads like characteristics than doxorubicin. Hence, the 3-amino pyranoquinolinone 2a-c can act as a good starting point for designing a new therapeutically useful anticancer agent.

\subsection{Anti-Cancer Activity}

\subsubsection{In-Vitro Anticancer Activity Using Ehrlich Ascites Carcinoma Cells (EAC) Cell Line}

The cytotoxicity of five compounds $\mathbf{2 a - c}$ and $\mathbf{4 a}-\mathbf{b}$ were examined on Ehrlich Ascites Carcinoma cells (EAC). The Antitumor efficacy of the compounds against EAC cell lines was demonstrated compared to doxorubicin. It is clear from the results in Table 2 and Figure 4, that the three 3-amino pyranoquinolinone 2a-c showed significant activity $\left(\mathrm{IC}_{50}=31.1,29.2\right.$ and $\left.27.7 \mu \mathrm{M}\right)$ respectively which is nearly as potent as the reference drug (doxorubicin, $\mathrm{IC}_{50}=39.5$ $\mu \mathrm{M})$. Compound $2 \mathrm{c}$ showed the higher activity among the 3 -amino pyranoquinolinone serieswith $\mathrm{IC}_{50}=27.7 \mu \mathrm{M}$. The reason for the higher reactivity of the amines can be explained by the presence of the bioactive 3-aminopyrane and quinolinone moieties in one molecular frame, quinolinone is known with its activity towards tumor cells. It has been reported that quinolones are known as potent antitumor agents because they target topoisomerase II enzyme and are considered as therapeutic promise [34]. It has been reported also that the activity of quinolinone depends on attack of topoisomerease IV (DNA gyrase) in microbes and topoisomerease II in animals that in eukaryotes, DNA gyrase and topoisomerease IV is functionally replaced by two isoenzymes: topoisomerease IIa and IIb, a170 and b $180 \mathrm{kDa}$ protein, respectively [35] [36]. Also interested are the 2-pyrones themselves, as some of the 2-pyrones with hydroxyl group at $\mathrm{C} 4$ position were reported to be biologically active [37]. In our study, the presence of the aliphatic chain beside the amino group in 3-amino pyranoquinolinone 2a-c is playing a vital role to improve the efficiency of the quinoline moiety as anti-tumor inhibitors, where it was found the presence of the butyl chain which seems to be the main responsible factor for $2 \mathrm{c}$ superiority over the other two compounds 2a-b and may give an idea about the possible importance of extended alkyl group in nitrogen $N 1$ at quinolinone ring to enhance activity. Considerable evidence indicated that as longer as the alkyl group at position $\mathrm{N}-1$ as higher as antitumor activity and increase affinity towards topoisomerease II [38]. 
Table 2. Tumor cell growth inhibition expressed as inhibitory concentration $\mathrm{IC}_{50}(\mu \mathrm{M})$ in the presence of the synthesized compounds.

\begin{tabular}{cc}
\hline Compound & ${ }^{\mathrm{a}} \mathrm{IC}_{50}(\mathrm{in} \mu \mathrm{g} / \mathrm{mL})$ \\
\hline $2 \mathrm{a}$ & 31.1 \\
2b & 29.2 \\
2c & 27.7 \\
4a & 25.9 \\
4b & 24.3 \\
Doxorubicin & 39.5 \\
\hline
\end{tabular}

${ }^{\mathrm{a}} \mathrm{IC}_{50}$, compound concentration required to inhibit tumour cell proliferation by $50 \%($ mean $\pm \mathrm{SD}), \mathrm{n}=3$.

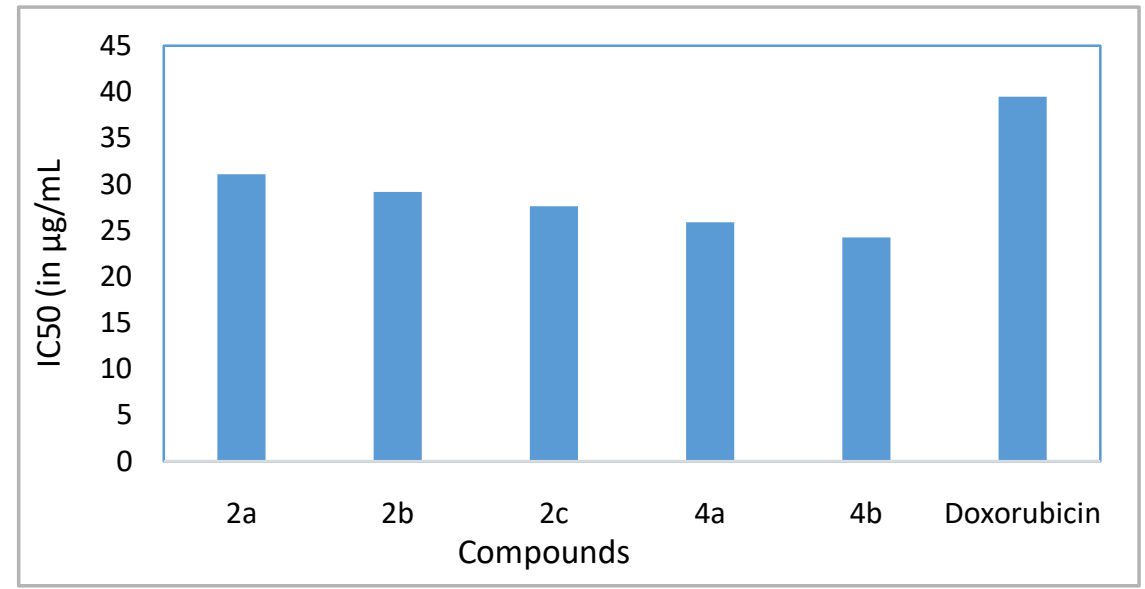

Figure 4. In-vitro anticancer activity of pyrano[3,2-c]quinolone compounds 2a-c and 4a-b on Ehrlich Ascites Carcinoma cells (EAC) cell line expressed as inhibitory concentration $\mathrm{IC}_{50}(\mu \mathrm{M})$.

Moreover, the most potent compound in this study was triazinopyranoquinolinone compound $4 \mathrm{~b}\left(\mathrm{IC}_{50}=24.4 \mu \mathrm{M}\right)$ which was found to be more potent than the reference drug (doxorubicin) $\left(\mathrm{IC}_{50}=39.5 \mu \mathrm{M}\right)$ and also they found to be more active than the starting material $2 \mathrm{c}\left(\mathrm{IC}_{50}=27.7 \mu \mathrm{M}\right)$ this may be attributed to the presence of triazine ring which enhance the anti-cancer activity.

\subsubsection{In-vitro Anticancer Activity Using Liver Cancer Cell Line (Hep-G2) and Breast Cancer Cell Line MCF-7}

The pyrano[3,2-c] quinolone compounds $2 \mathrm{a}-\mathrm{c}$ and $4 \mathrm{a}-\mathrm{b}$ were evaluated for their in vitro antitumor effects using the standard 3-(4,5-dimethylthiazol-2-yl)-2, 5-diphenyltetrazolium bromide (MTT) method against a panel of two human tumour cell lines: liver cancer cell line Hep-G2 and breast cancer cell line MCF-7. 5-fluorouracil (5-FU), which are one of the most effective anticancer agents, was used as a reference drug. Our results showed that some of the pyrano[3,2-c] quinolone compounds $2 \mathrm{a}-\mathrm{c}$ and $\mathbf{4 a - b}$ exhibited a moderate to strong growth inhibition activity on the tested cell lines in comparison to the reference anticancer drugs. The relationship between surviving fraction and drug concen- 
tration was plotted to obtain the survival curve of the two cell lines. The response parameter calculated was the $\mathrm{IC}_{50}$ value, which corresponds to the concentration required for $50 \%$ inhibition of cell viability. The key results obtained for compounds $\mathbf{2 a - c}$ and $\mathbf{4 a - b}$ toward liver cancer cell line (Hep-G2) and breast cancer cell line MCF-7 are shown in Table 3 and Figure 5. The percentage of viable cells was calculated as percent of cell viability by the following formula \% cell viability $=$ (Mean absorbance in test wells/Mean absorbance in control wells) 100. The cell viability was observed following 24,48 and $72 \mathrm{~h}$ of exposure to all compounds at doses of $0.5,1,2,4,8,16,32,62.5,125,250,500$ and $1000 \mu \mathrm{M}$ of compounds (see supporting data). The results revealed that compounds $2 \mathrm{c}$ with butyl group at N-1 position of the quinolone core with $\mathrm{IC}_{50}=10.7 \mu \mathrm{M}$ at $72 \mathrm{hr}$ was found to be more potent than the reference drug (5-flurouracil) $\left(\mathrm{IC}_{50}=11.2\right.$ $\mu \mathrm{M})$, On the other hand, compounds $4 \mathbf{a}-\mathbf{b}$ with triazine moiety exhibited strong activity against HepG2 cell line with $\mathrm{IC}_{50}: 8.3$ and $6.7 \mu \mathrm{M}$ at $72 \mathrm{hr}$ respectively, which was found to be more potent than the reference drug 5-flurouracil $\left(\mathrm{IC}_{50}=\right.$ 11.2 $\mu \mathrm{M}$ ). And 11.1 and $9.7 \mu \mathrm{M}$ at $72 \mathrm{hr}$ respectively against MCF-7 cell line compared with reference drug 5-flurouracil $\left(\mathrm{IC}_{50}=11.6 \mu \mathrm{M}\right)$.

Table 3. Evaluation of $\mathrm{IC}_{50}$ of compounds $2 \mathrm{a}-\mathrm{c}$ and $4 \mathrm{a}-\mathrm{b}$ to liver cancer cell line (Hep-G2) and breast cancer cell line MCF-7 compared with reference drug, 5-flurouracil.

\begin{tabular}{|c|c|c|c|c|c|c|}
\hline \multirow[t]{2}{*}{ Compound } & \multicolumn{3}{|c|}{$\begin{array}{c}\text { Hep-G2 } \\
\mathrm{IC}_{50}(\mu \mathrm{g} / \mathrm{mL})\end{array}$} & \multicolumn{3}{|c|}{$\begin{array}{c}\text { MCF-7 } \\
\mathrm{IC}_{50}(\mu \mathrm{g} / \mathrm{mL})\end{array}$} \\
\hline & $\mathrm{IC}_{50} / 24 \mathrm{hr}$ & $\mathrm{IC}_{50} / 48 \mathrm{hr}$ & $\mathrm{IC}_{50} / 72 \mathrm{hr}$ & $\mathrm{IC}_{50} / 24 \mathrm{hr}$ & $\mathrm{IC}_{50} / 48 \mathrm{hr}$ & $\mathrm{IC}_{50} / 72 \mathrm{hr}$ \\
\hline $2 a$ & 50.2 & 92.8 & 51.1 & 80.2 & 35.9 & 20.9 \\
\hline $2 b$ & 54.6 & 63.6 & 39.2 & 71.3 & 42.4 & 21.5 \\
\hline $2 c$ & 32.4 & 25.1 & 10.7 & 34.5 & 28.4 & 19.9 \\
\hline $4 a$ & 12.8 & 19.6 & 8.3 & 14.9 & 18.7 & 11.1 \\
\hline $4 \mathrm{~b}$ & 10.7 & 15.4 & 6.7 & 13.1 & 16.4 & 9.7 \\
\hline 5-flurouracil & 11.5 & 19.5 & 11.2 & 12.1 & 21.6 & 11.6 \\
\hline
\end{tabular}

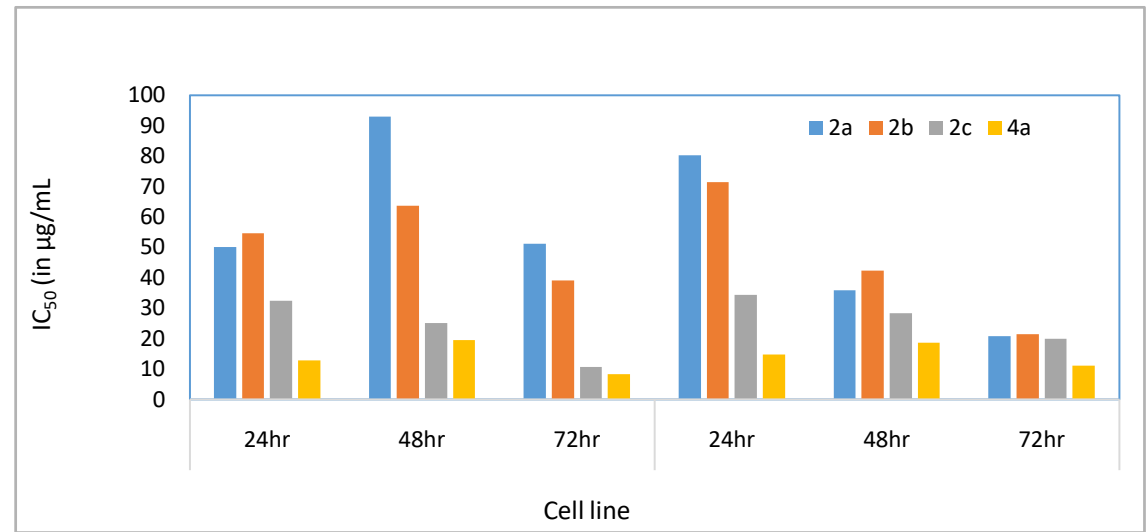

Figure 5. In-vitro anticancer activity of pyrano[3,2-c]quinolone compounds $2 \mathrm{a}-\mathrm{c}$ and 4a-b on liver cancer cell line (Hep-G2) and breast cancer cell line MCF-7 expressed as inhibitory concentration $\mathrm{IC}_{50}(\mu \mathrm{M})$ for $24 \mathrm{~h}, 48 \mathrm{~h}$ and $72 \mathrm{~h}$. 


\section{Conclusion}

A series of the pyrano[3,2-c]quinolonine analogues were evaluated for its anticancer activity. The screening results revealed that compounds $4 \mathrm{a}-\mathrm{b}$ were found as the most active candidates of the series against anticancer activity compared to the reference doxorubicin and 5-flurouracil against the three human tumour cell lines: Ehrlich Ascites Carcinoma cells (EAC), liver cancer cell line Hep-G2 and breast cancer cell line MCF-7. A molecular docking study was employed to investigate their binding and functional properties as TOP2B inhibitors. Compounds $2 \mathrm{a}-\mathrm{c}$ showed a good binding mode with docking score values $(-7.46$, $\left.-7.64,-8.27 \mathrm{kcal} \cdot \mathrm{mol}^{-1}\right)$ respectively compared with 5-flurouracil $(-10.07$ $\mathrm{kcal} \cdot \mathrm{mol}^{-1}$ ). Compound $2 \mathrm{c}$ has an extended alkyl side chain, compared to $2 \mathrm{a}$ and 2b which may result in a new electrostatic interaction, with topoisomeraseII that can significantly enhance the 3 -amino pyranoquinolinone compounds $2 \mathrm{a}-\mathrm{c}$ potency. The results suggested that presence of butyl group ring at $N$-position of the pyrano[3,2-c]quinolone structural motif seems to be an important position for anticancer activity. However, addition of triazine ring to compound $2 \mathrm{c}$ showed a significant alteration of the bioactive conformer of the parent scaffold and outcome with compounds $4 \mathrm{a}-\mathrm{b}$ as the most potent candidates of the series. In summary, pyrano[3,2-c] quinolone compounds $4 \mathbf{a}-\mathbf{b}$ have been confirmed as a useful lead compound which can be developed for the clinical trial for its therapeutic use.

\section{Conflicts of Interest}

The authors declare no conflicts of interest regarding the publication of this paper.

\section{References}

[1] Obaid Afzal, S.K., Haider, R., Ali, R., Kumar, R., Jaggi, M. and Bawa, S. (2015) A Review on Anticancer Potential of Bioactive Heterocycle Quinoline. European Journal of Medicinal Chemistry, 97, 871-910. https://doi.org/10.1016/j.ejmech.2014.07.044

[2] Hisham, A. and Abd, E. (1997) A Novel One Step Synthesis of Pyrano[3,2-c]quinolines and a Transformation into 3,3-bis-(4-hydroxy-2-quinolone)aryl-methanes. Pharmazie, 52, 28 -31.

[3] Upadhyay, K.D. and Shah, A.K. (2019) Evaluation of Pyrano[3,2 C]quinoline Analogues as Anticancer Agents. Anti-Cancer Agents in Medicinal Chemistry, 19, 1285-1292. https://doi.org/10.2174/1871520619666190308122734

[4] Upadhyay, K.D., Dodia, N.M., Khunt, R.C., Chaniara, R.S. and Shah, A.K. (2018) Synthesis and Biological Screening of Pyrano[3,2-c]Quinoline Analogues as Anti-Inflammatory and Anticancer Agents. ACS Medicinal Chemistry Letters, 9, 283-288. https://doi.org/10.1021/acsmedchemlett.7b00545

[5] Isaka, M., Kongsaeree, M.T.P. and Thebtaranonth, Y. (2001) Structures of Cordypyridones A-D, Antimalarial N-Hydroxy- and N-Methoxy-2-pyridones from the Insect Pathogenic Fungus Cordyceps nipponica. The Journal of Organic Chemistry, 66, 4803-4808. https://doi.org/10.1021/jo0100906 
[6] Hanawa, F., Fokialakis, N. and Skaltsounis, A.L. (2004) Photo-Activated DNA Binding and Antimicrobial Activities of Furoquinoline and Pyranoquinolone Alkaloids from Rutaceae. Planta Medica, 70, 531-535. https://doi.org/10.1055/s-2004-827153

[7] Chen, J.J., Chen, P.H., Liao, C.H., Huang, S.Y. and Chen, I.S. (2007) Antitubercular Dihydroagarofuranoid Sesquiterpenes from the Roots of Microtropis Fokienensis. Journal of Natural Products, 70, 1444-1448. https://doi.org/10.1021/np070186g

[8] Cantrell, C.L., Schrader, K.K., Mamonov, L.K., Sitpaeva, G.T., Kustova, T.S., Dunbar, C. and Wedge, D.E. (2005) Isolation and Identification of Antifungal and Antialgal Alkaloids from Haplophyllum sieversii. Journal of Agricultural and Food Chemistry, 53, 7741-7748. https://doi.org/10.1021/jf051478v

[9] Michael, J.P. (2008) Quinoline, Quinazoline and Acridonealkaloids. Natural Product Reports, 25, 166-187. https://doi.org/10.1039/B612168N

[10] Chen, I.S., Tsai, I.L., Wu, T.S., Pezzuto, J.M., Lu, M.C., Chai, H., Suh, N. and Teng, C.M. (1994) Chemical and Bioactive Constituents from Zanthoxylum Simulans. Journal of Natural Products, 57, 1206-1211. https://doi.org/10.1021/np50111a003

[11] Singla, P., Luxami, V. and Paul, K. (2015) Triazine as a Promising Scaffold for Its Versatile Biological Behavior. European Journal of Medicinal Chemistry, 102, 39-57. https://doi.org/10.1016/j.ejmech.2015.07.037

[12] Costanzo, A., et al. (1999) Benzodiazepine Receptor Ligands. 4. Synthesis and Pharmacological Evaluation of 3-Heteroaryl-8-Chloropyrazolo[5,1-c][1,2,4] Benzotriazine 5-Oxides. Journal of Medicinal Chemistry, 42, 2218-2226. https://doi.org/10.1021/jm981126y

[13] Irannejad, H., et al. (2010) Synthesis and in Vitro Evaluation of Novel 1,2,4-Triazine Derivatives as Neuroprotective Agents. Bioorganic \& Medicinal Chemistry, 18, 4224-4230. https://doi.org/10.1016/j.bmc.2010.04.097

[14] Bennett, G.B., et al. (1981) A Potent, New, Sedative-Hypnotic Agent: 5,7-Dihydro5,5,7,7-Tetramethyl-3-(3-Nitrophenyl)Furo[3,4-e]-as-Triazine 4-Oxide. Journal of Medicinal Chemistry, 24, 490-496. https://doi.org/10.1021/jm00137a003

[15] Congreve, M., et al. (2012) Discovery of 1,2,4-Triazine Derivatives as Adenosine A(2A) Antagonists Using Structure Based Drug Design. Journal of Medicinal Chemistry, 55, 1898-1903. https://doi.org/10.1021/jm201376w

[16] Trepanier, D.L., Shriver, K.L. and Eble, J.N. (1969) Aryl-Substituted Triazines with Antidepressant Activity. Journal of Medicinal Chemistry, 12, 257-260.

https://doi.org/10.1021/jm00302a013

[17] Liu, C., et al. (2010) Discovery of 4-(5-(Cyclopropylcarbamoyl)-2-Methylphenylamino)5-Methyl-N-Propylpyrrolo[1,2-f][1,2,4]Triazine-6-Carboxamide (BMS-582949), a Clinical p38Alpha MAP Kinase Inhibitor for the Treatment of Inflammatory Diseases. Journal of Medicinal Chemistry, 53, 6629-6639. https://doi.org/10.1021/jm100540x

[18] Sztanke, K., et al. (2007) Identification of Antibacterial and Antiviral Activities of Novel Fused 1,2,4-Triazine Esters. Bioorganic \& Medicinal Chemistry, 15, 5480-5486. https://doi.org/10.1016/j.bmc.2007.05.048

[19] Hay, M.P., et al. (2004) DNA-Targeted 1,2,4-Benzotriazine 1,4-Dioxides: Potent Analogues of the Hypoxia-Selective Cytotoxin Tirapazamine. Journal of Medicinal Chemistry, 47, 475-488. https://doi.org/10.1021/jm030399c

[20] Hassanin, H.M. (2019) Convenient Approach to Novel Tetracyclic-Fused Pyranoquinolinone Compounds from 6-n-Butyl-3-Amino-4-Hydroxypyrano[3,2-c]Quino- 
linone. ARKAT USA, 1-13.

https://doi.org/10.24820/ark.5550190.p010.937

[21] Hawtin, R.E., et al. (2010) Voreloxin Is an Anticancer Quinolone Derivative that Intercalates DNA and Poisons Topoisomerase II. PLOS ONE, 5, e10186. https://doi.org/10.1371/journal.pone.0010186

[22] Hande, K.R. (2008) Topoisomerase II Inhibitors. Update on Cancer Therapeutics, 3, 13-26. https://doi.org/10.1016/j.uct.2008.02.001

[23] Pommier, Y., et al. (2010) DNA Topoisomerases and Their Poisoning by Anticancer and Antibacterial Drugs. Chemistry \& Biology, 17, 421-433. https://doi.org/10.1016/j.chembiol.2010.04.012

[24] Molecular Operating Environment (MOE), Chemical Computing Group, Montreal, Canada 2015. http://www.chemcomp.com

[25] D’Arpa, P. and Liu, L.F. (1989) Topoisomerase-Targeting Antitumor Drugs. Biochimica et Biophysica Acta, 989, 163-177. https://doi.org/10.1016/0304-419X(89)90041-3

[26] Wentland, M.P., et al. (1993) Mammalian Topoisomerase II Inhibitory Activity of 1-Cyclopropyl-6,8-Difluoro-1,4-Dihydro-7-(2,6-Dimethyl-4-Pyridinyl)-4-Oxo-3-Q uinolinecarb Oxylic Acid and Related Derivatives. Journal of Medicinal Chemistry, 36, 2801-2809. https://doi.org/10.1021/jm00071a010

[27] Wang, L.D., et al. (2009) A Strategy to Control Transmission of Schistosoma Japonicum in China. The New England Journal of Medicine, 360, 121-128. https://doi.org/10.1056/NEJMoa0800135

[28] Marrison, L.R., Dickinson, J.M. and Fairlamb, I.J.S. (2002) Bioactive 4-Substituted6-Methyl-2-Pyrones with Promising Cytotoxicity against A2780 and K562 Cell Lines. Bioorganic \& Medicinal Chemistry Letters, 12, 3509-3513. https://doi.org/10.1016/S0960-894X(02)00824-7

[29] Elsea, S.H., et al. (1993) Drug Features that Contribute to the Activity of Quinolones against Mammalian Topoisomerase II and Cultured Cells: Correlation between Enhancement of Enzyme-Mediated DNA Cleavage in Vitro and Cytotoxic Potential. Antimicrobial Agents and Chemotherapy, 37, 2179-2186. https://doi.org/10.1128/AAC.37.10.2179

[30] Romero, I.A., et al. (2003) Changes in Cytoskeletal and Tight Junctional Proteins Correlate with Decreased Permeability Induced by Dexamethasone in Cultured Rat Brain Endothelial Cells. Neuroscience Letters, 344, 112-116.

https://doi.org/10.1016/S0304-3940(03)00348-3

[31] Buttke, T.M., McCubrey, J.A. and Owen, T.C. (1993) Use of an Aqueous Soluble Tetrazolium/Formazan Assay to Measure Viability and Proliferation of Lymphokine-Dependent Cell Lines. Journal of Immunological Methods, 157, 233-240. https://doi.org/10.1016/0022-1759(93)90092-L

[32] Berridge, M.V., Herst, P.M. and Tan, A.S. (2005) Tetrazolium Dyes as Tools in Cell Biology: New Insights into Their Cellular Reduction. Biotechnology Annual Review, 11, 127-152. https://doi.org/10.1016/S1387-2656(05)11004-7

[33] Chen, X., et al. (2010) Quantitative Proteomics Analysis of Cell Cycle-Regulated Golgi Disassembly and Reassembly. The Journal of Biological Chemistry, 285, 7197-207. https://doi.org/10.1074/jbc.M109.047084

[34] Grassi, T.F., et al. (2007) DNA Damage in Multiple Organs after Exposure to Chlorhexidine in Wistar Rats. The International Journal of Hygiene and Environmental Health, 210, 163-167. https://doi.org/10.1016/j.ijheh.2006.09.001 
[35] Wu, C.-C., et al. (2013) On the Structural Basis and Design Guidelines for Type II Topoisomerase-Targeting Anticancer Drugs. Nucleic Acids Research, 41, 10630-10640. https://doi.org/10.1093/nar/gkt828

[36] (2015) Small-Molecule Drug Discovery Suite 2015-2: Glide, Version 6.7. Schrödinger, LLC, New York.

[37] Maestro 9.9.013, Schrödinger, LLC, Portland, OR. http://www.schrodinger.com/

[38] Friesner, R.A., et al. (2006) Extra Precision Glide: Docking and Scoring Incorporating a Model of Hydrophobic Enclosure for Protein-Ligand Complexes. Journal of Medicinal Chemistry, 49, 6177-6196. https://doi.org/10.1021/jm051256o 